\title{
Prevalence and determinants of self-reported ocular morbidity and utilization of eye services in Sri Lanka: results from a national population- based survey
}

\author{
K Edussuriya ${ }^{1}$, E Schmidt ${ }^{2}$, G V S Murthy ${ }^{3,4}$, E Jolley², C Banagala ${ }^{5}$, C Gilbert ${ }^{3}$ on behalf of the Sri \\ Lanka National Blindness, Visual Impairment and Disability Steering Committee and Survey Team ${ }^{6}$
}

\begin{abstract}
Introduction Data on ocular morbidity is essential for planning primary and referral eye care services.

Objectives Determine the prevalence and causes of selfreported ocular morbidity and eye care service utilization in Sri Lanka among adults $\geq 40$ years of age.

Methods Multistage, stratified, cluster random sampling was used to select a nationally representative sample aged $\geq 40$ years. All participants were administered a questionnaire to assess ocular morbidity they had experienced in the previous month and the pattern of service utilization for reported eye problems. The interviews were conducted by a team of trained investigators at the clinical examination site before they underwent an eye examination.
\end{abstract}

Results 5779 of those presenting for a clinical examination were interviewed among 6713 enumerated (86.1\%). The prevalence of self-reported ocular morbidity was $89.9 \%$ [95\% Confidence Interval (Cl): 89.0-90.6\%]. Near vision impairment was the commonest problem reported $(72.1 \%$; $95 \% \mathrm{Cl}: 70.8-73.3 \%)$ followed by distance vision impairment (36.2\%; 95\% Cl: 34.9-37.5\%). Among those reporting an eye problem, $31.4 \%$ sought treatment. $49.4 \%$ of those seeking care utilized private facilities. Financial constraints, perceptions that the condition was not serious or had insufficient impact on day-to-day tasks were the most important reasons for not accessing care.

Conclusions Ocular morbidities are common in the Sri Lanka population; however utilization of services is relatively low, particularly for asymptomatic illnesses. It is important that the service planners take into account geographical and social inequalities and focus the services on underserviced areas and disadvantaged social groups.
Ceylon Medical Journal 2018; 63 (S2): s45-s52

DOI: http://doi.org/10.4038/cmj.v63i5.8742

\section{Introduction}

Ocular morbidity is defined as the presence of any eye condition, which is perceived as important or significant from either a clinician or a client perspective [1]. Therefore, ocular morbidity encompasses all conditions that lead to vision impairment or blindness (e.g. cataract, diabetic retinopathy, glaucoma etc.) as well as eye problems that are not sight-threatening yet impact the patient's functioning and quality of life (discharge, tearing, irritability, diminished near vision etc.). The global agestandardized prevalence of blindness is estimated at $1.9 \%$ and moderate/severe visual impairment (MSVI) at 10.4\% for adults aged $\geq 50$ years [2]. The prevalence of blindness in South Asia (4.4\%) is higher than the global average [2]. The prevalence of self-reported ocular morbidity is also high, ranging between $13-33 \%$ in Nigeria, Kenya, Pakistan and China [1;3-6]. A much higher prevalence has recently been reported among adults in other countries at $57 \%$ in Canada [7], 67\% in Fiji [8] and 91\% in Timor Leste, [9].

Patients' health seeking behavior for eye care has been studied recently in a variety of settings [1,4,8-11], with many studies highlighting that the demand for eye care services is low, with many patients delaying access to treatment or not seeking care at all [11]. Recent studies in Kenya [1] and Nigeria [4] found that only half of those experiencing eye problems sought treatment or advice from trained professionals, and that eye care may be ranked

\begin{abstract}
${ }^{1}$ Department of Ophthalmology, General Hospital, Kandy, Sri Lanka, ${ }^{2}$ Sightsavers UK, Haywards Heath, West Sussex, UK, ${ }^{3}$ Department of Clinical Research, London School of Hygiene and Tropical Medicine, London. UK, ${ }^{4}$ Indian Institute of Public Health, Hyderabad, India, ${ }^{5}$ Sri Lanka College of Ophthalmologists, Colombo, Sri Lanka, ${ }^{6}$ In addition to the above, other members of the Sri Lanka National Blindness, Visual Impairment and Disability Steering Committee and Survey Team: Palitha G Mahipala, Asela Pradeep Abeydeera, Ahamed Jeza, KMG Gamage, Saman Senanayake, Sunil Fernando, Lakmini Dissanayake, Nirmi Vitharana, Nimal Edirisinghe, Sunil Settinayake, RP Kumara, S A H K Wimalarathne, Attapathu AH, Priyangani MD, Bandara KRTC, Chamin Rathnayake, Y G Upali Jayarathne, Souvik Bandhopadhyaya, Hira Ballabh Pant, Mahesh Dorairaj, Sandeep Bhuttan.
\end{abstract}

Correspondence: GVSM, e-mail: <Gvs.Murthy@Ishtm.ac.uk>. Received 19 February 2018 and revised version accepted 23 June 2018.

(i) This is an open-access article distributed under the terms of the Creative Commons Attribution License, which permits unrestricted use, distribution, and reproduction in any medium, provided the original author and source are credited. 
lower in priority than other health problems. A study in Cameroon highlighted that more than $60 \%$ of people did not seek treatment for eye care compared with $88 \%$ who sought treatment for fever within a week of onset [12]. Evidence suggests that an individual's decision-making on whether and where and when to seek treatment is complex and is determined by an array of intrinsic (disease severity, patient characteristics, perceived seriousness etc.) and extrinsic factors (cost of care, transportation links, perceived efficacy of treatment and past experience with the health system) [13]. In low and middle-income countries (LMICs) patients' demand for eye care is often restricted by the limited number of eye care facilities, particularly those at secondary and tertiary levels, resulting in increased time and transport costs required for access, as was recently reported from Sri Lanka [14].

The situation in Sri Lanka is unique as health indicators are comparable to those in high income countries [15]. There has been a significant improvement in Sri Lanka's health system and health outcomes over the past 8 decades, particularly in maternal and child health [15]. However data are not available for eye care.

Available evidence emphasises that client behaviour is context specific as the availability of facilities plays an important role. Generating evidence on ocular morbidity is important as it helps in developing a context-specific plan for eye care services in a country. Such data does not exist in Sri Lanka. Therefore, a study was commissioned by the Ministry of Health to conduct a study on a nationally representative sample of adults aged $\geq 40$ years of age the main focus of which was blindness and visual impairment. An assessment of self-reported ocular morbidity, utilization of eye care services and barriers to accessing services was included in this survey.

\section{Methods}

Detailed methodology of the national survey has been described in a companion paper in this issue. In brief, multi-stage stratified cluster random sampling was used to identify a cross-sectional, nationally representative sample aged $\geq 40$ years. All nine provinces and a random sample of divisional secretariats were included.

The following parameters were used to determine the sample size: prevalence of blindness (presenting vision) among those aged $\geq 40$ years $-2.5 \%$; confidence interval $-95 \%$; allowable error -0.02 ; precision $-80 \%$; design effect -1.5 and a response rate of $85 \%$.

The estimated sample size was 6,600 but to ensure that all 25 districts were included, it was inflated to 6800 by adding two clusters. Thus it was planned to cover 100 respondents across 68 clusters in the country.

An initial house-to-house enumeration yielded respondents who were asked to attend a temporary clinical examination site set up in a convenient location within each cluster.
Two trained interviewers verified participants' eligibility and administered the questions to elicit a history of eye problems, source of treatment and barriers to treatment. Participants were specifically asked if they had experienced an eye problem/complaint in the month preceding the survey and whether and when they had sought care. For participants that reported experiencing more than one eye problem/complaint, all their problem/ complaints were recorded. Respondents who had an eye problem but had not sought care were asked about barriers preventing them from accessing eye care services: Participants could give multiple responses. Written informed consent was obtained from all eligible participants.

All the core staff underwent intensive training for one week prior to the start of the survey followed by a pilot survey. Fieldwork took place over a one-year period from 2013 to 2014.

The study protocol was reviewed and approved by the Institutional Ethics Committees of the London School of Hygiene and Tropical Medicine, London, UK, the Faculty of Medicine, University of Colombo, Sri Lanka and the Indian Institute of Public Health, Hyderabad, India.

The data were analysed using STATA 13.0 (StataCorp LP, Texas, USA). Descriptive analyses and cross tabulations with calculation of Pearson chi squared tests were performed. Firstly, univariate analysis was done, to assess associations between socio-demographic factors and the risk of self-reported ocular morbidity. The sociodemographic variables included age, gender, socioeconomic status (SES), literacy status, place of residence, province of residence and ethnic group. Socio economic status was a composite measure based on family possessions. Family possessions like four-wheelers, twowheelers, computer, refrigerators, colour television, telephone etc. were first assessed and a score calculated and cumulated for the family. The cumulative scores were then divided into four quartiles from lowest (quartile 1) to highest (quartile 4). For the sake of analysis the lowest 2 quartiles were classified as lower socio-economic status while the highest 2 quartiles were classified as upper socioeconomic status. Literacy was categorized as illiterate, less than primary school, less than secondary school and beyond secondary school (O level and above). Further analyses were undertaken using logistic regression. All socio-demographic variables which were significant at 0.05 level in univariate analysis were included in the multivariate regression analysis. All tests are two sided, and the odds ratios (OR) and 95\% CI quoted are derived from logistic regression models.

\section{Results}

A total of 6713 persons aged $\geq 40$ years were eligible for the survey. $5779(86.1 \%)$ presented for the clinical examination and 5193 were interviewed. The mean age of participants was $56.7( \pm 10.9)$ years and $59 \%$ were female. 
The prevalence of ocular morbidity in the one-month period was $89.9 \%$ (95\% CI: 89.0-90.6\%) (Table 1). The prevalence of ocular morbidity was similar across most sociodemographic parameters, and was significantly higher in participants with higher socio-economic status (SES) (adjusted OR 1.4 (95\% CI 1.2-1.6\%, p<0.001) (Table 1). The majority $(81.9 \%)$ reporting an eye problem in the past month said that they still had the problem at the time of the survey. Near vision impairment was the commonest problem reported $(72.1 \%$; 95\% CI: $70.8-73.3 \%)$ followed by distance vision impairment (36.2\% ; 95\% CI: 34.9-37.5\%) (Table 2). Irritability/itching eyes, watering/tearing and pain were the other commonly reported eye symptoms. (Table 1).

A high proportion of individuals who were blind or moderately/severely visually impaired from all causes did not seek care $(65.9 \%)$, and the proportion was even higher amongst those severely visually impaired from refractive error $(77.8 \%)$ or cataract (83.9\%). Only 155 participants provided information on how much time had elapsed before they sought treatment. 19.3\% (30/155) had attended a facility within 48 hours while nearly half $(47.4 \%$; 74/155) sought treatment six or more months after they noticed the eye problem. Nearly half $(49.4 \% ; 802 / 1631)$ used private facilities and $39.4 \%$ (642/1631) used government health facilities. Others visited an eye camp (3.4\%), or used traditional medicines or eye medicines available at home.

Less than a third $(31.4 \%)$ of those reporting an eye problem had sought treatment for their condition (Table 3). Reasons for not accessing eye care services (3512 persons) are shown by visual acuity and cause of visual impairment (Table 3). Financial constraints and lack of time were the most important reasons for not accessing care ( $25.6 \%$ and $15.1 \%$ respectively). Financial constraints was an even greater barrier for those who were visually impaired (39.1-47.6\%). Only a relatively small proportion of individuals who were visually impaired reported the problem as not being serious enough to seek treatment or they could manage their activities (10.3-23.8\%).

Females were significantly more likely to report an eye problem than males (adjusted OR 1.24, 95\% CI: $1.05-$ 1.48 ) as were participants with lower SES (Adjusted OR1.5; $95 \%$ CI: 1.2 - 1.8). Participants living in the Southern province had the highest odds of reporting an eye problem (Adjusted OR-4.0; 95\% CI: 2.0-7.7) compared to those in the North Central province, which had the lowest prevalence of ocular morbidity (Table 4).

Sex and marital status were not associated with whether eye care services had been accessed. However the following groups had significantly higher odds of using services in the adjusted analysis: higher SES, living in the Southern, Central, Sabaragamuva and Western provinces, increasing age, urban residence, the better educated and those belonging to the Sinhala or Moor ethnic group. Distance from the nearest health facility did not affect the prevalence of reported ocular morbidity or access to eye care services (Table 4).

Participants who reported a foreign body in the eye or an eye injury, or dry or painful eyes or problems with near vision were more likely to have accessed services than those with other symptoms. Only $30.6 \%$ (1133/3703) of those who complained of difficulty with near vision and $29.1 \%(542 / 1859)$ of those who complained of difficulty in seeing at a distance had accessed eye care services (Table 5).

The mean monthly expenditure on general health care in a 30-day recall period was SLR 1310 (US\$ 8.5). Similar levels of expenditure were reported in the households, where participants aged $\geq 40$ years reported an eye problem. What these expenses related to was not investigated.

\section{Discussion}

The high prevalence of self-reported OM in this study is not surprising as, in contrast to other studies of OM which included people of all ages $[1,3,4]$, this survey focused on those aged $\geq 40$ years, the majority of whom would have presbyopia. For example, in the Nigerian survey, which included all age groups, $84.6 \%$ of those aged $\geq 55$ years reported ocular morbidity [4]. The main types of morbidity reported were also similar with the majority experiencing near vision problems and gradual loss of vision. Similar to other studies, a higher prevalence of self-reported OM in Sri Lanka was associated with being a female and belonging to lower SES [1,4].

Only a third of those who had eye complaints, as in other studies in South Asia sought treatment [6,11,16,17]. The reasons for not seeking care were also similar with the lack of perceived seriousness of the problem $[8,11]$ and financial constraints [14;17-19] being the main reasons.

In the present study financial constraints were the leading reason for not seeking care for participants with visually impairment from cataract and refractive errors. Accurate information on the cost of health care or eye care in Sri Lanka are not available in the published literature but a recent study in a hospital in Sri Lanka estimated the out-of-pocket expenditure for cataract surgery to be SLR 25,407 (US\$ 165.4). The provider cost for the delivering cataract surgery was SLR 15,668 (US\$ 102) [20]. Although the recently the Government of Sri Lanka provides intraocular lenses at no cost to the patient, the costs for cataract surgery will be significantly higher when patients need to buy their own lenses, especially the high-end costly lenses. Therefore, the finding that financial constraints is a significant barrier to care for people with visual impairment is not surprising. This was also confirmed by the data from the multivariate analysis, which shows that those belonging to more disadvantaged groups (lower SES, poorer literacy, resident in rural areas) are less likely to seek care than other groups in the population. 
Table 1. Prevalence of self-reported ocular morbidity and association with socio-demographic characteristics

\begin{tabular}{|c|c|c|c|c|}
\hline \multirow[t]{2}{*}{ Characteristics } & \multirow{2}{*}{$\frac{\text { Interviewed }}{N}$} & \multicolumn{2}{|c|}{ Reporting Ocular Morbidity in past month } & \multirow[t]{2}{*}{$95 \% C I$} \\
\hline & & $N$ & Prevalence (\%) & \\
\hline Respondents & 5779 & 5193 & 89.8 & $89.0-90.6$ \\
\hline \multicolumn{5}{|l|}{ Age groups } \\
\hline $40-49 y$ & 1708 & 1520 & 89.0 & $87.4-90.4$ \\
\hline $50-59 y$ & 1859 & 1685 & 90.6 & $89.2-91.9$ \\
\hline $60-69 y$ & 1424 & 1276 & 89.6 & $87.9-91.1$ \\
\hline $70+y$ & 788 & 712 & 90.4 & $88.0-92.2$ \\
\hline \multicolumn{5}{|l|}{ Gender } \\
\hline Male & 2356 & 2089 & 88.7 & $87.3-89.9$ \\
\hline Female & 3423 & 3104 & 90.7 & $89.6-91.6$ \\
\hline \multicolumn{5}{|l|}{ Education } \\
\hline$\geq$ Secondary & 4120 & 3689 & 89.5 & $88.6-90.4$ \\
\hline$<$ Secondary & 1659 & 1504 & 90.7 & $89.1-92.0$ \\
\hline \multicolumn{5}{|l|}{ Socio-economic status } \\
\hline Lower & 3262 & 2983 & 91.4 & $90.4-92.4$ \\
\hline Higher & 2517 & 2210 & 87.8 & $86.4-89.0$ \\
\hline \multicolumn{5}{|l|}{ Residence } \\
\hline Rural & 5102 & 4575 & 89.7 & $88.8-90.5$ \\
\hline Urban & 677 & 618 & 91.3 & $88.9-93.2$ \\
\hline \multicolumn{5}{|l|}{ Marital Status } \\
\hline Currently Married & 4399 & 3950 & 89.8 & $88.9-90.6$ \\
\hline Currently Unmarried/ Widowed & 1380 & 1243 & 90.1 & $88.4-91.5$ \\
\hline \multicolumn{5}{|l|}{ Ethnic Groups } \\
\hline Moors & 180 & 165 & 91.7 & $86.6-94.9$ \\
\hline Sinhala & 4546 & 4106 & 90.3 & $89.4-91.1$ \\
\hline Tamils & 1053 & 922 & 87.6 & $85.4-89.4$ \\
\hline \multicolumn{5}{|l|}{ Province } \\
\hline Western & 1648 & 1485 & 90.1 & $88.6-91.5$ \\
\hline Central & 1122 & 1040 & 92.7 & $91.0-94.1$ \\
\hline North Western & 586 & 513 & 87.5 & $84.6-90.0$ \\
\hline Eastern & 499 & 450 & 90.2 & $87.2-92.5$ \\
\hline Northern & 469 & 413 & 88.1 & $84.8-90.7$ \\
\hline Sabaragamuwa & 510 & 465 & 91.2 & $88.4-93.3$ \\
\hline North Central & 346 & 288 & 83.2 & $78.9-86.8$ \\
\hline Uva & 348 & 300 & 86.2 & $82.1-89.4$ \\
\hline Southern & 251 & 239 & 95.2 & $91.7-97.3$ \\
\hline \multicolumn{5}{|l|}{ Distance from health centre } \\
\hline$\leq 2 \mathrm{kms}$ & 2591 & 2334 & 90.1 & 88.9- 91.2 \\
\hline$>2 \mathrm{kms}$ & 2815 & 2528 & 89.8 & $88.6-90.9$ \\
\hline
\end{tabular}

Table 2. Frequency and type of self-reported ocular morbidity

\begin{tabular}{lccc}
\hline & $N(5779)$ & $\%$ & $95 \% C I$ \\
\hline Reported an eye problem in the preceding month & 5193 & 89.9 & $89.0-90.6$ \\
Main eye problem reported in preceding month* & & & \\
Problem with near vision & 3742 & 72.1 & $70.8-73.3$ \\
Problem with distance vision & 1879 & 36.2 & $34.9-37.5$ \\
Irritable, sore, burning eyes & 757 & 14.6 & $13.6-15.6$ \\
Watering & 592 & 11.4 & $10.6-12.3$ \\
Pain in the eye & 447 & 8.6 & $7.9-9.4$ \\
Foreign body in eye & 83 & 1.60 & $1.3-2.0$ \\
Red eye with discharge & 50 & 0.96 & $0.73-1.3$ \\
Dry eye & 19 & 0.37 & $0.23-0.57$ \\
Floaters in the eye & 19 & 0.37 & $0.23-0.57$ \\
Diplopia (Double vision) & 7 & 0.13 & $0.06-0.28$ \\
Others & 3 & 0.06 & $0.002-0.18$ \\
\hline
\end{tabular}

*Total more than 5193 as some participants had more than one complaint 
Table 3. Reasons for not seeking care among respondents with self-reported ocular morbidity

\begin{tabular}{|c|c|c|c|c|c|c|c|c|c|c|}
\hline & \multicolumn{2}{|c|}{ All respondents } & \multicolumn{2}{|c|}{$\begin{array}{l}V A>6 / 12 \\
\text { both eyes }\end{array}$} & \multicolumn{2}{|c|}{$\begin{array}{l}\text { Moderate/severe } \\
\text { visual impairment } \\
\text { and blind } \\
(<6 / 18 \text { better eye })\end{array}$} & \multicolumn{2}{|c|}{$\begin{array}{l}\text { Refractive errors } \\
\text { with severe visual } \\
\text { impairment }\end{array}$} & \multicolumn{2}{|c|}{$\begin{array}{l}\text { Cataract with } \\
\text { severe visual } \\
\text { impairment }\end{array}$} \\
\hline & $N(5193)$ & $\%$ & $N(3295)$ & $\%$ & $N$ & $\%$ & $N$ & $\%$ & $N$ & $\%$ \\
\hline Sought treatment for eye problem & 1631 & 31.4 & 935 & 28.4 & 335 & 33.2 & 12 & 22.2 & 15 & 16.1 \\
\hline Did not seek any treatment & 3512 & 67.6 & 2328 & 70.6 & 665 & 65.9 & 42 & 77.8 & 78 & 83.9 \\
\hline Did not respond & 50 & 1.0 & 32 & 1.0 & 9 & 0.9 & 0 & - & 0 & - \\
\hline Total & 5193 & 100.0 & 3295 & 100.0 & & 100.0 & & 100.0 & & 100.0 \\
\hline \multicolumn{11}{|c|}{ Reasons reported for not seeking treatment* } \\
\hline Financial reasons (lack of money) & 900 & 25.6 & 482 & 20.7 & 260 & 39.1 & 20 & 47.6 & 33 & 42.3 \\
\hline Lack of time & 531 & 15.1 & 407 & 17.5 & 58 & 8.7 & 5 & 11.9 & 3 & 3.8 \\
\hline $\begin{array}{l}\text { Did not think it was serious enough } \\
\text { to seek treatment/ could manage } \\
\text { all activities }\end{array}$ & 407 & 11.6 & 1076 & 46.2 & 148 & 22.3 & 10 & 23.8 & 8 & 10.3 \\
\hline Used eye medicines available at home & 233 & 6.6 & 150 & 6.4 & 44 & 6.6 & 0 & - & 4 & 5.1 \\
\hline Accepted it as it is part of ageing & 123 & 3.5 & 53 & 2.3 & 47 & 7.1 & 1 & 2.4 & 8 & 10.3 \\
\hline No one to accompany/ lack of escort & 96 & 2.7 & 36 & 1.5 & 42 & 6.3 & 2 & 4.8 & 8 & 10.3 \\
\hline Got better without any treatment & 80 & 2.3 & 55 & 2.4 & 17 & 2.6 & 1 & 2.4 & 4 & 5.1 \\
\hline Too far & 56 & 1.6 & 29 & 1.2 & 20 & 3.0 & 1 & 2.4 & 4 & 5.1 \\
\hline Did not know where to go & 41 & 1.2 & 18 & 0.8 & 15 & 2.3 & 0 & - & 5 & 6.4 \\
\hline Fear & 3 & 0.1 & 2 & 0.1 & 1 & 0.1 & 0 & - & 0 & - \\
\hline Other serious health problems & 3 & 0.1 & 1 & 0.04 & 2 & 0.3 & 0 & - & 0 & - \\
\hline Other family priorities & 2 & 0.06 & 1 & 0.04 & 0 & - & 0 & - & 0 & - \\
\hline
\end{tabular}

*Some participants reported more than one reason

Table 4. Adjusted odds of reporting eye problems and seeking treatment for eye problems

\begin{tabular}{|c|c|c|c|c|}
\hline \multirow[b]{2}{*}{ Variable } & \multicolumn{2}{|c|}{ Reporting eye problem } & \multicolumn{2}{|c|}{ Accessing treatment for eye problem } \\
\hline & $\begin{array}{l}\text { Univariate analysis } \\
\text { OR }[95 \% \text { CI }]\end{array}$ & $\begin{array}{l}\text { Multivariate analysis } \\
\text { Adjusted OR }[95 \% \text { CI] }\end{array}$ & $\begin{array}{l}\text { Univariate analysis } \\
\text { Adjusted OR }[95 \% \text { CI] }\end{array}$ & $\begin{array}{l}\text { Multivariate analysis } \\
\text { Adjusted OR [95\% CI] }\end{array}$ \\
\hline \multicolumn{5}{|l|}{ Gender } \\
\hline Male & Ref & Ref & $1.03[0.9-1.2]$ & - \\
\hline Female & $\begin{array}{l}1.24[1.05-1.48] \\
X^{2}-6.21 ; p=0.01\end{array}$ & $\begin{array}{l}1.2[1.02-1.4] \\
\mathrm{X}^{2}-5.01 ; \mathrm{p}=0.02\end{array}$ & $\begin{array}{l}\text { Ref } \\
X^{2}-0.25 ; p=0.6\end{array}$ & $\begin{array}{l}- \\
-\end{array}$ \\
\hline \multicolumn{5}{|c|}{ Socio-economic status } \\
\hline Lower & $1.5[1.2-1.8]$ & $1.4[1.2-1.7]$ & Ref & Ref \\
\hline Higher & $\begin{array}{l}\operatorname{Ref} \\
X^{2}-20.7 ; p<0.001\end{array}$ & $\begin{array}{l}\text { Ref } \\
X^{2}-16.4 ; p<0.001\end{array}$ & $\begin{array}{l}1.6[1.4-1.8] \\
X^{2}-55.9 ; p<0.001\end{array}$ & $\begin{array}{l}1.4[1.2-1.6] \\
X^{2}-20.5 ; p<0.001\end{array}$ \\
\hline \multicolumn{5}{|l|}{ Province } \\
\hline North Central & Ref & Ref & Ref & Ref \\
\hline Uva & $1.3[0.8-1.9]$ & $1.1[0.7-1.7]$ & $1.0[0.6-1.6]$ & $0.33[0.1-0.9]$ \\
\hline North Western & $1.4[0.97-2.06]$ & $1.3[0.9-1.96]$ & $2.3[1.6-3.6]$ & $4.3[2.5-7.2]$ \\
\hline Northern & $1.5[1.0-2.2]$ & $1.2[0.8-1.8]$ & $1.3[0.8-2.0]$ & $8.3[3.6-19.3]$ \\
\hline Western & $1.8[1.3-2.5]$ & $1.6[1.2-2.3]$ & $5.5[3.7-8.0]$ & $5.5[3.2-9.5]$ \\
\hline Eastern & $1.8[1.2-2.8]$ & $1.8[1.2-2.9]$ & $1.5[0.96-2,3]$ & $1.6[0.96-2.8]$ \\
\hline Sabaragamuwa & $2.1[1.4-3.2]$ & $1.6[1.03-2.45]$ & $4.1[2.7-6.3]$ & $8.8[4.8-16.4]$ \\
\hline Central & $2.5[1.8-3.7]$ & $2.7[1.8-4.1]$ & $4.8[3.2-7.0]$ & $7.0[4.5-11.0]$ \\
\hline Southern & $\begin{array}{l}4.0[2.0-7.7] \\
X^{2}-9.61 ; p=0.002\end{array}$ & $\begin{array}{l}3.7[1.8-4.1] \\
X^{2}-11.6 ; p<0.001\end{array}$ & $\begin{array}{l}4.1[2.6-6.4] \\
X^{2}-261.4 ; p<0.001\end{array}$ & $\begin{array}{l}5.9[3.2-10.8] \\
X^{2}-85.23 ; \mathrm{p}<0.001\end{array}$ \\
\hline \multicolumn{5}{|l|}{ Age Category } \\
\hline $40-49 y$ & Ref & - & Ref & Ref \\
\hline $50-59 y$ & $1.2[1.0-1.5]$ & - & $1.7[1.5-2.1]$ & $1.97[1.6-2.3]$ \\
\hline $60-69 y$ & $1.1[0.8-1.3]$ & - & $2.4[2.0-2.9]$ & $2.8[2.3-3.4]$ \\
\hline$\geq 70 \mathrm{y}$ & $\begin{array}{l}1.2[0.9-1.5] \\
X^{2}-0.7 ; p=0.4\end{array}$ & $\begin{array}{l}- \\
-\end{array}$ & $\begin{array}{l}2.7[2.2-3.3] \\
X^{2}-134.7 ; p<0.001\end{array}$ & $\begin{array}{l}3.1[2.4-4.0] \\
X^{2}-148.1 ; p<0.001\end{array}$ \\
\hline \multicolumn{5}{|l|}{ Residence } \\
\hline Rural & Ref & - & Ref & Ref \\
\hline Urban & $\begin{array}{l}1.2[0.9-1.6] \\
X^{2}-1.71 ; p=0.19\end{array}$ & $\begin{array}{l}- \\
-\end{array}$ & $\begin{array}{l}1.9[1.7-2.3] \\
X^{2}-57.1 ; \mathrm{p}<0.001\end{array}$ & $\begin{array}{l}1.3[1.02-1.7] \\
\mathrm{X}^{2}-4.36 ; \mathrm{p}=0.04\end{array}$ \\
\hline
\end{tabular}




\begin{tabular}{|c|c|c|c|c|}
\hline \multirow[b]{2}{*}{ Variable } & \multicolumn{2}{|c|}{ Reporting eye problem } & \multicolumn{2}{|c|}{ Accessing treatment for eye problem } \\
\hline & $\begin{array}{l}\text { Univariate analysis } \\
\text { OR }[95 \% \mathrm{CI}]\end{array}$ & $\begin{array}{l}\text { Multivariate analysis } \\
\text { Adjusted OR }[95 \% \text { CI] }\end{array}$ & $\begin{array}{l}\text { Univariate analysis } \\
\text { Adjusted OR }[95 \% \text { CI] }\end{array}$ & $\begin{array}{l}\text { Multivariate analysis } \\
\text { Adjusted OR }[95 \% \text { CI] }\end{array}$ \\
\hline \multicolumn{5}{|l|}{ Education } \\
\hline$\geqq$ Secondary & Ref & - & $1.7[1.4-1.9]$ & $1.7[1.4-2.0]$ \\
\hline \multirow[t]{2}{*}{$<$ Secondary } & $1.1[0.9-1.4]$ & - & Ref & Ref \\
\hline & $\mathrm{X}^{2}-1.62 ; \mathrm{p}=0.2$ & & $\mathrm{X}^{2}-54.4 ; \mathrm{p}<0.001$ & $\mathrm{X}^{2}-37.2 ; \mathrm{p}<0.001$ \\
\hline \multicolumn{5}{|l|}{ Marital Status } \\
\hline Currently Married & Ref & - & Ref & - \\
\hline \multirow[t]{2}{*}{ Currently Unmarried/ Widowed } & $1.03[0.84-1.26]$ & - & $1.1[0.98-1.3]$ & - \\
\hline & $\mathrm{X}^{2}-0.09 ; \mathrm{p}=0.8$ & - & $\mathrm{X}^{2}-2.99 ; \mathrm{p}=0.08$ & - \\
\hline \multicolumn{5}{|l|}{ Ethnic Groups } \\
\hline Sinhala & Ref & - & $2.5[2.1-3.0]$ & $1.9[1.5-2.4]$ \\
\hline Tamils & $0.7[0.61-0.93]$ & - & Ref & Ref \\
\hline \multirow[t]{2}{*}{ Moors } & $1.2[0.69-2.02]$ & - & $2.0[1.4-3.0]$ & $0.99[0.5-1.8]$ \\
\hline & $\mathrm{X}^{2}-2.41 ; \mathrm{p}=0.1$ & - & $\mathrm{X}^{2}-64.9 ; \mathrm{p}<0.001$ & $\mathrm{X}^{2}-6.4 ; \mathrm{p}=0.01$ \\
\hline \multicolumn{5}{|l|}{ Distance from health facility } \\
\hline$\leq 2 \mathrm{kms}$ & $1.03[0.9-1.2]$ & - & Ref & Ref \\
\hline \multirow[t]{2}{*}{$>2 \mathrm{kms}$} & Ref & - & $0.65[0.57-0.73]$ & $0.98[0.83-1.15]$ \\
\hline & $\mathrm{X}^{2}-0.11 ; \mathrm{p}=0.74$ & - & $\mathrm{X}^{2}-49.01 ; \mathrm{p}<0.001$ & $\mathrm{X}^{2}-0.06 ; \mathrm{p}=0.8$ \\
\hline
\end{tabular}

Table 5. Accessing treatment in different eye complaints

\begin{tabular}{lccc}
\hline Self-reported eye problem & $N$ & \multicolumn{2}{c}{ Sought treatment } \\
& & $n$ & $\%$ \\
\hline Foreign body in eye/Injury & 83 & 44 & 53.0 \\
Dry eye & 19 & 8 & 42.1 \\
Pain in the eye & 447 & 160 & 35.6 \\
Problem with near vision & 3703 & 1133 & 30.6. \\
Problem with distance vision & 1859 & 542 & 29.2 \\
Watering & 587 & 146 & 24.9 \\
Floaters & 18 & 4 & 22.2 \\
Irritable, sore, burning eyes & 754 & 161 & 21.3 \\
Diplopia & 6 & 1 & 16.7 \\
Red eye with discharge & 50 & 7 & 14.0 \\
\hline
\end{tabular}

Distance to facilities and costs of transport were not major barriers to access service in this study. However, lack of time and someone to accompany participants to the facility was an issue, particularly for those with visual impairment. Fear of surgery was not an important barrier unlike in a previous study [14]. The chronic nature of many of the conditions experienced by patients over a long period of time may be one reason why eye care was not sought [21], as demonstrated in this study where persons with acute conditions like foreign body/eye injury, dry eye and pain had higher rate of seeking care.

Although Sri Lanka has an extensive network of primary care facilities, only secondary and tertiary care hospitals have equipment and trained personnel for specialist care, including eye care [22]. Our findings suggest that many non-visually impairing conditions, particularly near vision problems experienced by many patients can be managed by the primary level facilities which provide care closer to the community and at affordable costs and this option needs to be considered. Primary level eye care, has been scaled up across Sri Lanka over the last few years, being a priority of the National Programme for the prevention of blindness (2013 to 2017) [23]. However the shortage of ophthalmologists and the lack of trained mid-level ophthalmic personnel, coupled with lack of diagnostic equipment at the primary level adds to the challenge of providing effective primary eye care.

Integration of eye health into primary health care provides an opportunity to improve access to eye care services at the community level [24]. Delays in presentation of potentially sight-threatening acute conditions like injuries and red eyes can be reduced by effective primary health care and a responsive referral system. Primary eye care encompasses the diagnosis, treatment and referral of eye conditions at the lowest level of the health system and is generally delivered by primary health care workers [24]. Unfortunately the skills of primary level personnel are often poor and basic competencies are also not achieved in many countries [25,26].

The strengths of the present study are the representative sample and the large sample size, which included all the districts in the country. The same interviewers, who were fluent in Sinhala and Tamil, the two main languages in Sri Lanka, collected all the data. Limitations are that ocular morbidity was not assessed in the younger population, and costs of specific eye care interventions were not obtained.

In summary, the study highlights the high prevalence of ocular morbidity in older adults as well as a high unmet need, particularly for conditions which require specialist eye care services (i.e. for refractive errors, cataract and presbyopia) or which could be managed at the primary level of service delivery (red eyes, itching/irritable eyes). 
The recent expansion of primary eye care may help to address this need. A major challenge in accessing specialist eye care services was the cost that would be incurred, and approaches that reduce out of pocket expenditure for the poorer members of the community need to be considered.

\section{Acknowledgements}

We acknowledge the support from the members of the Steering Committee, the Sri Lanka College of Ophthalmologists, the Vision2020 Secretariat, Ministry of Health and Family Welfare, Sri Lanka, Sightsavers Country Office, Sri Lanka and all the supervisors and field investigators (Madhuni Wijepala, Subhashini Deshappriya, Rasika Damayanthi, Dinusha Sandamali, Ashanti de Silva, Chaturika Madushani, Menaka Rathnayake, Madusha Priyadarshini, Nadeesha Dilhani, Gaya Shanthi) and data entry operators (Sunethra Thennakoon, Kumuduni Sriyalatha) who worked with great diligence in collecting the data from the survey participants. We thank all the survey participants for giving us the time and opportunity to interact with them to collect critical data.

We would like to thank Sightsavers for financial support of the overall study and CBM for financial contributions to the disability component of the survey.

\section{Conflicts of interest}

All authors declare that they do not have any conflicts of interest.

\section{References}

1. Kimani K, Lindfield R, Senyonjo L, Mwaniki A, Schmidt E. Prevalence and causes of ocular morbidity in Mbeere district, Kenya. Results of a population-based survey. PLoS One 2013; 8: e700009.

2. Stevens GA, White RA, Flaxman SR, et al. Global prevalence of vison impairment and blindness: Magnitude and temporal trends,1990-2010. Ophthalmology 2013; 120: 2237-384.

3. Adegbehingbe BO, Majengbasan TO. Ocular health status of rural dwellers in south-western Nigeria. Aust J Rural Health 2007; 15: 269-72.

4. Senyonjo L, Lindfield R, Mahmoud A, Kimani K, Sanda S, Schmidt E. Ocular morbidity and health seeking behavior in Kwara State, Nigeria: Implications for delivery of eye care services. PLoS One 2014; 9: e104128.

5. Hussain A, Awan H, Khan MD. Prevalence of non-vision impairing conditions in a village in Chakwal district, Punjab, Pakistan. Ophthalmic Epidemiol 2004; 11: 413-26.

6. Bai Y, Yi H, Zhang L, et al. An investigation of vision problems and the vision care system in rural China. Southeast Asian J Trop Me Public Health 2014; 45: 1464-73.
7. Perruccio AV, Badley EM, Trope GE. A Canadian population-based study of vision problems: assessing the significance of socio-economic status. Can J Ophthalmol 2010; 45: 477-83

8. Brian G, Maher L, Ramke J, Palagyi A. Eye care in Fiji: a population-based study of use and barriers. Ophthalmic Epidemiol 2012; 19: 43-51.

9. Palagyi A, Ramke J, du Toit R, Brian G. Eye care in TimorLeste: a population-based study of utilization and barriers. Clin Exp Ophthalmol 2008; 36: 47-53.

10. Ahmad K, Zwi AB, Tarantola DJ, Chaudhry TA. Selfperceived barriers to eye care in a hard-to-reach population: the Karachi Marine Fishing Communities Eye and General Health Survey. Invest Ophthalmol Vis Sci. 2015; 56: 1023-32.

11. Peng Y, Tao QS, Liang YB, et al. Eye care use among rural adults in China: the Handan Eye Study. Ophthalmic Epidemiol. 2013; 20: 274-80.

12. Lindfield R, Gees E, Nangia EN, Mearkle R, Senyonjo L, Oye J, Celestin N, Schmidt E. Understanding eye health seeking behavior: implications for policy and service planning. A mixed-method study in South West Cameroon, 2015 (unpublished).

13. Ravenell JE, Whitaker EE, Johnson WE. According to him: Barriers to healthcare among African-American men. $J$ National Med Assoc 2008; 100: 1153-60.

14. Holmes W, Shajehan R, Kitnasamy S, Abeywickrama C, Arsath Y, Gnanaraj F. Impact of vision impairment and self-reported barriers to vision care: The views of elders in Nuwara Eliya district, Sri Lanka. Global Public Health 2016; 19: $1-14$.

15. Karunathilake IM. Health changes in Sri Lanka: benefits of primary health care and public health. Asia Pacific J Public Health 2012; 24: 663-71.

16. Nirmalan PK, Katz J, Robin AL, et al. Utilization of eye care services in rural South India: the Aravind Comprehensive Eye Survey. Br J Ophthalmol. 2004; 88: 1237-41.

17. Kovai V, Krishnaiah S, Shamanna BR, Thomas R, Rao GN. Barriers to accessing eye care services among visually impaired populations in rural Andhra Pradesh, South India. Indian J Ophthalmol 2007; 55: 365-71.

18. Fletcher AE, Donoghue M, Devavaram J, et al. Low uptake of eye services in rural India: a challenge for programs of blindness prevention. Arch Ophthalmol. 1999; 117: 1393-9.

19. Dandona R, Dandona L, Naduvilath TJ, McCarty CA, Rao GN. Utilisation of eyecare services in an urban population in southern India: the Andhra Pradesh eye disease study. Br J Ophthalmol 2000; 84: 22-7.

20. Perera C, Silva DD, Perera LRP. Estimation of provider cost and the out-of-pocket expenditure for cataract surgery at a base hospital. Ceylon Med J 2016; 61: 200.

21. National Health Strategic Master Plan 2016-2025. Vol. IV. Health Administration and HRH. Ministry of Health, Sri Lanka. http://www.health.gov.lk/enWeb/HMP2016-2025/ Health\%20\%20Admin\%20-\%20\%20HRH.pdf. Accessed 28th July 2017. 
22. Vision2020 Sri Lanka: right to Sight. National Program for Prevention of Blindness, Sri Lanka. Comprehensive Eye Care Plan ((2013-2017 Five Years) https://www.iapb.org/ wp-content/uploads/Sri-Lanka-Action-Plan-2013-17.pdf. Accessed August 32017.

23. Du Toit R, Faal HB, Etya'ale D et al. Evidence for integrating eye health into primary health care in Africa:a health systems strengthening approach. BMC Health Serv Res 2013; 13: 102.

24. Kalua K, Gichangi M, Barassa E, et al. Skills of general health workers in primary eye care in Kenya, Malawi and Tanzania. Hum Resour Health 2014; 12 (Suppl 1): S2.

25. Mafwiri MM, Jolley E, Hunter J, Gilbert CE, Schmidt E. Mixed methods evaluation of a primary care training programme for primary health workers in Morogoro, Tanzania. BMC Nurs 2016; 15: 41.

26. Byamukama E, Courtright P. Knowledge, skills, and productivity in primary eye care among health workers in Tanzania:need for reassessment of expectations? Int Health 2010; 2: 247-52. 